DIW BERLIN

Discussion Papers

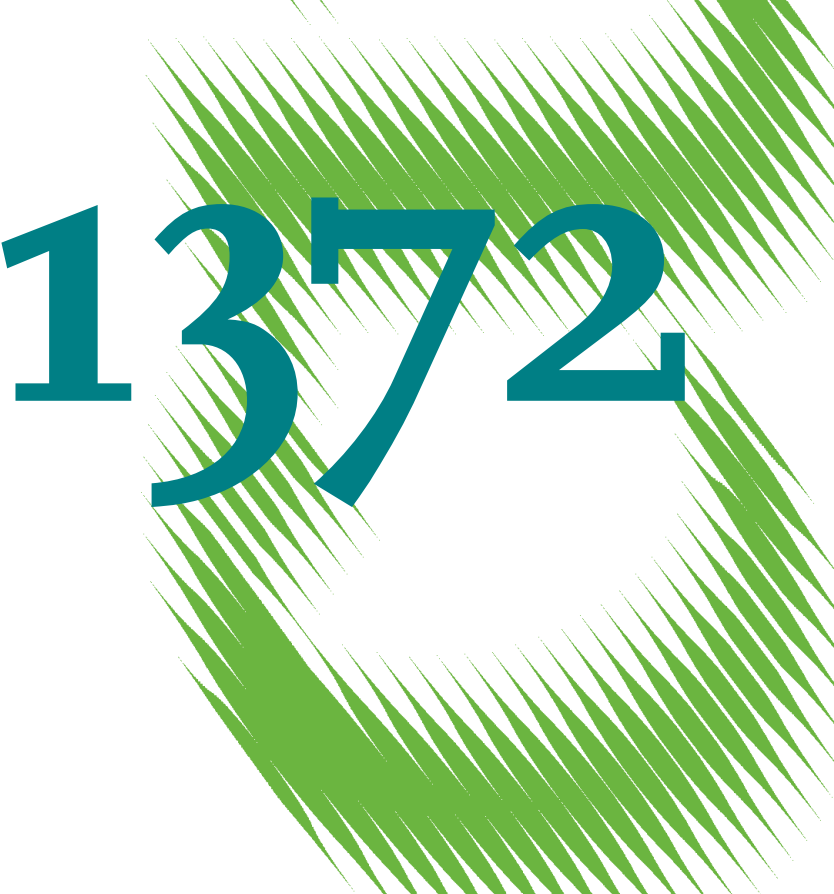

Elasticities of Supply for the US Natural Gas Market 
Opinions expressed in this paper are those of the author(s) and do not necessarily reflect views of the institute.

IMPRESSUM

(C) DIW Berlin, 2014

DIW Berlin

German Institute for Economic Research

Mohrenstr. 58

10117 Berlin

Tel. $+49(30) 89789-0$

Fax +49 (30) $89789-200$

http://www.diw.de

ISSN print edition $1433-0210$

ISSN electronic edition 1619-4535

Papers can be downloaded free of charge from the DIW Berlin website:

http://www.diw.de/discussionpapers

Discussion Papers of DIW Berlin are indexed in RePEc and SSRN:

http://ideas.repec.org/s/diw/diwwpp.html

http://www.ssrn.com/link/DIW-Berlin-German-Inst-Econ-Res.html 


\title{
Elasticities of supply for the US natural gas market
}

\author{
Micaela Ponce \\ Universität Potsdam* \\ mponce@uni-potsdam.de \\ AnNe NeumanN \\ Universität Potsdam and DIW Berlin ${ }^{\dagger}$ \\ anne.neumann@uni-potsdam.de
}

April 2, 2014

\begin{abstract}
In this paper we investigate natural gas producer's reactions to changes in market prices. We estimate price elasticities of aggregated supply in the most competitive market for natural gas: the United States. Using monthly time series data form 1987 to 2012 our analysis is based on an Autoregressive Distributed Lag (ARDL) Bound Cointegration approach to obtain short and long-run elasticities of natural gas supply. Results suggest that natural gas producers in a competitive market are not able to react to prices in the very short-run but respond inelastic in the long-run. These findings are not only of great value for policy makers but also for gas market modelers.
\end{abstract}

JEL-Clasification: L95, Q41, C22, C32

Keywords: Elasticity of supply, natural gas, ARDL, ECM, competitive markets

\footnotetext{
*Faculty of Economics and Social Sciences, Chair for Economic Policy, August-Bebel-Str. 89, D-14482 Potsdam, Germany.

${ }^{\dagger}$ Faculty of Economics and Social Sciences, Chair for Economic Policy, August-Bebel-Str. 89, D-14482 Potsdam, Germany and German Institute for Economic Research, DIW Berlin.
} 


\section{INTRODUCTION}

$\mathrm{H}$ Istorically, the United States has been one of the largest producers of natural gas worldwide reflecting an increasing rate of production over the $20^{\text {th }}$ century. After World War II the natural gas industry expanded quickly led by the developments in infrastructure but during the 50's the industry faced strong wellhead price regulations ${ }^{1}$. Although positive effects derived from this market regulation (prices fell) collateral damage arose with it as well. As a consequence, investments in exploration activities where discouraged due to the low market price, which led to natural gas supply shortages (Mc Avoy, 2000). Shortages worsened and became much more visible during the 1973-1975 energy crisis as factories switched their petroleum boilers to natural gas boilers (Cleveland, 2009). The 1970ies shortages led to regulatory changes and in 1978 the Natural Gas Policy Act created the Federal Energy Regulatory Commission (FERC), and introduced natural price decontrols to re-stimulate domestic natural gas production. During the 80 's (see Figure 1) the natural gas production in the US plunged, but since then it has been rising continuously.

Although the United States has historically played a big part as a natural gas producer, it is only recently, as in 2009, that it became the largest producer worldwide (BP, 2013) reaching in 2012 a production level of around 681 billion cubic meters ( $24 \mathrm{tcf}$ ). As seen in Figure 1, this high increase in production can be partly explained by a large increase in proven reserves. Proven reserves have increased since the late 1990ies driven by technological advances in the exploration and extraction activities, like the application of horizontal drilling and hydraulic fracturing. Although horizontal drilling and hydraulic fracturing are not new discoveries ${ }^{2}$, it was the combination in advances of both technologies that made the extraction of natural gas out of shale formations possible and economical feasible, making shale gas today a significant contributor to natural gas supply in the United States. In 2011 natural gas produced out of shale gas basins accounted for 33 percent of national production (EIA, 2013).

For 2040 the Annual Energy Outlook reference scenario of the EIA forecasts a share of shale gas in production of 50 percent and a total increase of natural gas production of $10 \mathrm{tcf}$. This increase in supply is expected to be partly met by an increment in domestic consumption of $5.1 \mathrm{tcf}$. which is expected to be driven by an increase in all sectors of the economy, except for the residential sector, where improvements in appliance efficiency lead to mild consumption decreases (EIA, 2013). The exceeding production is expected to increase exports of natural gas boosting investments in the LNG sector.

With those inevitable changes in the natural gas markets, it becomes essential to understand how different market participants react to market signals. The contribution of this paper has a focus on the supplier's responsiveness to changes in prices: the price elasticity of supply in competitive market. From a regulator's perspective, elasticities of supply can deliver useful information in order to develop the right regulatory framework. It is also of relevance in the discussion on greenhouse gas abatement policies. In addition, elasticities of supply can provide important input for modeling exercises.

Throughout the existing empirical literature in the energy sector a strong focus on elasticities of demand rather than on elasticities of supply is evident. In a -still unconcluded- survey, Dahl (2007) finds over 1900 references on elasticities of demand from which 950 are econometric estimates. Out of these, 410 were conducted on electricity markets. The rest was divided into four groups: oil and oil products (260), natural gas (177), total energy demand (160) and coal (110), showing a strong emphasis of the elasticities literature on electricity markets.

\footnotetext{
${ }^{1}$ In the Phillips Petroleum Company v. Wisconsin case in 1954 the US Supreme Court of Justice declared the Federal Power Commission to regulate wellhead prices of natural gas producers.

${ }^{2}$ The first horizontal drill was recorded in Texon, Texas in 1929 (Raymond and Leffler, 2006).
} 


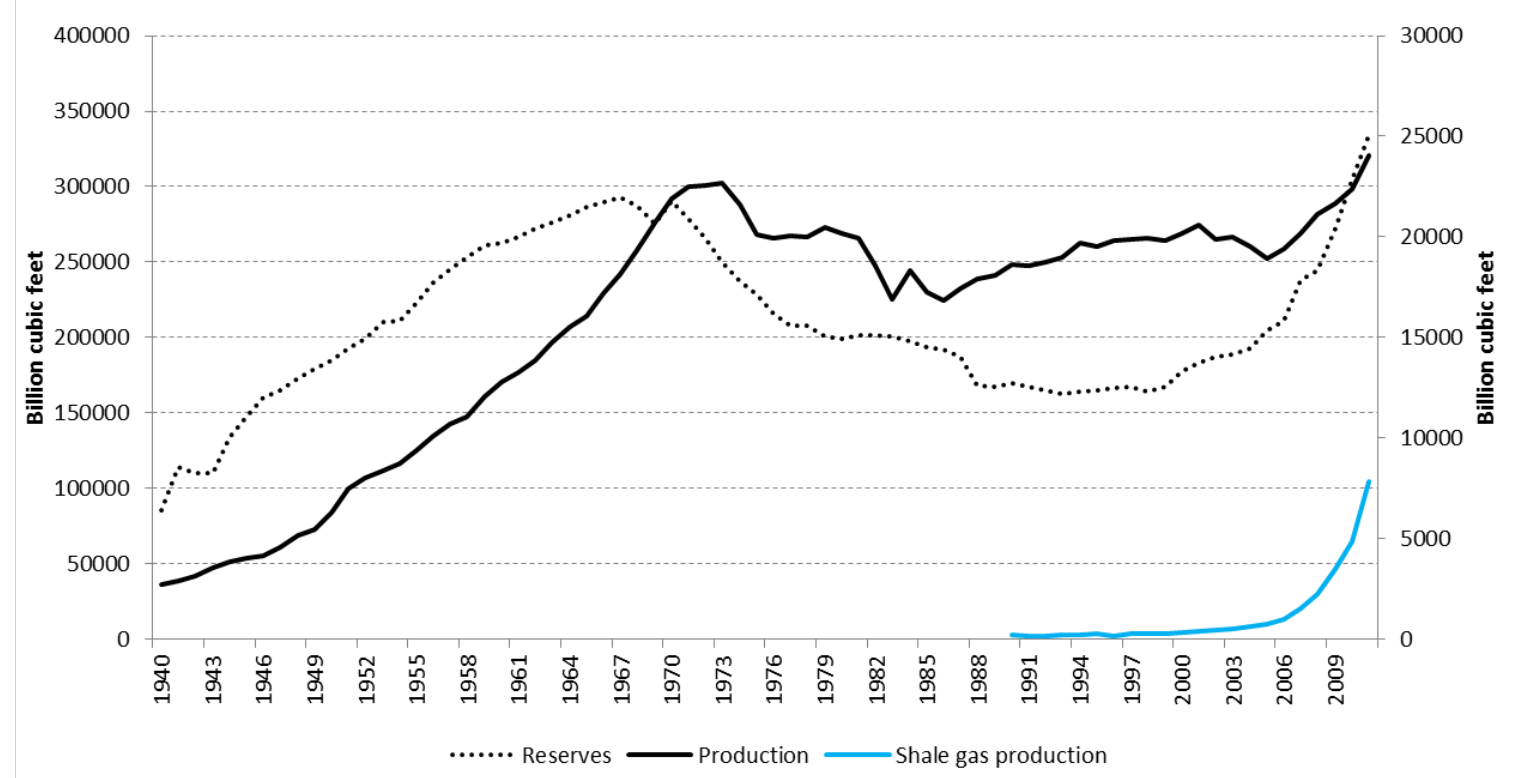

Figure 1: US Natural Gas Production vs. Reserves from 1940 to 2012

On the supply side econometric studies are very scarce and somewhat outdated. Dahl and Duggan (1996) conduct a survey where they compile several estimates for different energy sources. For natural gas only three studies are identified. Table 1 summarizes the main findings and provides some technical information. In a non-econometric approach Medlock III (2012) recently estimated the US price elasticity of supply at -1.52 . The existing empirical evidence for elasticities of supply is limited, especially in the past ten years and the range of estimates is enormous.

The purpose of our analysis is to provide empirical evidence on the supply responsiveness of natural gas to changes in price. Therefore we estimate the aggregate natural gas supply response to prices in a competitive fossil fuel market. Our approach is based on the theory of the firm where we consider the US natural gas market competitive. In such a market, the participating firm's goal is to maximize profits. Given the large number of firms in the market, whatever the firm produces can be sold at only one price. Each producer in a competitive market is a price taker constraining the price variable to the market's decision. Thus each producer will have to optimize the remaining variables that influence its profit function. That variable will be the amount of produced output. We assume that each firm has maximized profits and the quantity produced by a single firm will depend on the market price, the prices of substitutes and complements, and different input prices. The aggregated supply curve then is a function of input and output prices. The remainder of our analysis proceeds as follows. In section 2, we present our empirical strategy which is based on a cointegration approach. Section 3 presents the data used for the analysis and runs standard tests to validate our approach. The results of the analysis are shown in section 4 before providing interpretation and concluding remarks in section 5 .

\section{EMPIRICAL StRATEgy}

In general, aggregate natural gas supply $(q)$ in a competitive market can be explained as a function of input and output prices. An aggregated supply function would explain supply as a function of prices (input and output prices) and non-prices variables (restraints on production, technology 
Table 1: Elasticities of supply

\begin{tabular}{lllr}
\hline Study & Period & Sample Data & Elasticity \\
\hline $\begin{array}{l}\text { Erickson and Spann (1971) } \\
\text { new discoveries, regulation }\end{array}$ & $1946-1959$ & US & $0.69(\mathrm{~L})$ \\
$\begin{array}{l}\text { Barret (1992) } \\
\text { elasticities of supply }\end{array}$ & $1960-1990$ & US & \\
$\begin{array}{l}\text { Dahl (1992) } \\
\text { price elasticity of reserves, cost }\end{array}$ & $1986-1989$ & US sectional time series & 0.014 \\
$\begin{array}{l}\text { Chermak and Patrick (1995) } \\
\text { natural gas from tight sands, cost }\end{array}$ & $1988-1990$ & US & $0.40(\mathrm{~L})$ \\
Krichene (2002) & & Cross sectional time series & 1.05 to -1.92 \\
price elasticity of supply & $1918-1999$ & Worldwide & \\
& & Annual time series & 0.6 \\
& $1918-1973$ & Worldwide & \\
& & Annual time series & $0.28(\mathrm{~L})$ \\
& $1973-1999$ & Worldwide & $0.8(\mathrm{~L})$ \\
\end{tabular}

(L) indicates a long-run estimate

levels, resource constraints, etc.).

Given several data restrictions we explain natural gas supply in the United States as a function of natural gas prices $(P G)$, the price of a substitute $(P S)$, working gas in storages $(S)$, drilling activity $(D)$ and the season of the year (season) such that:

$$
q=f(P G, P S, S, D, \text { season })
$$

The IEA-28 Form available from the US EIA reports the financial performance of major energy companies from 1977 to 2009 categorized by fossil fuels. From the upstream costs reported during that period of time, drilling and equipment cost accounted for $23 \%$ to $60 \%$ of the total exploration and development costs. This is the reason why drilling activity is considered on this analysis as an explanatory variable of supply.

The amount of working dry gas in storage has a strong seasonal pattern and is a determinant of production. As known storage levels tend to be at their minimums after the winter season and tend to a gradual increase until the beginning of the next winter reaching its peak in October/ November and plunging in February/March depending on the length and the intensity of the winter season. Therefore producers would increase their production as the storage levels decrease and vice versa.

Including a substitute price in the supply function, arises out of the fact that natural gas and crude oil tend to be substitutes from the production sight. Hydrocarbon accumulation discoveries exist as combination of different fossil fuel states. Their composition varies in their fluid and gas mixture making petroleum engineers distinguish between five major types: black oil, volatile oil, retrograde gas, wet gas and dry gas for which their oil to gas ratio varies. This natural combination leads to a competition in extraction between crude oil and natural gas. So the amount of natural gas produced at the well will also depend on how the prices for crude oil develop.

The use of time series data for our analysis makes us aware to the spurious regression problem that arises when regressing non-stationary data. This was first studied by Yule (1926) and later analyzed by Granger and Newbold (1974). This means that two non-stationary time series can 
show correlation although no correlation relation among them exist. Therefore our empirical approach will be based on a non-stationarity model. The selection of an autoregressive distributed lag $(A R D L)$ cointegration approach is based on a series of convenient statistical properties. First, this method allows for the use of stationary $I(0)$ and non-stationary $I(1)$ variables thus avoiding inconveniences that arise with the use of low power of unit root tests. The data (as will be shown in section 3) requires a method that can be applied to stationary and non-stationary data. Second, the endogeneity problem that arises estimating supply elasticities, can be addressed. Monte-Carlo simulations conducted by Inder (1993) and Pesaran and Shin (1995) show that the ARDL approach yields precise estimates of long-run parameters and valid t-statistics even in the presence of endogenous explanatory variables. And third, an ARDL fit allows to simultaneously estimating short and long-run elasticities. The ARDL model uses both, the lagged values of the dependent variables (autoregressive) as well as the lagged values of the independent variables (distributed lag) to explain the dynamics of the dependent variable. Therefore equation 1 can be rewritten in an ARDL form as:

$$
\begin{aligned}
q_{t}= & \alpha_{0}+\sum_{j=1}^{a} \alpha_{j} \cdot q_{t-j}+\sum_{j=0}^{b} \beta_{j} \cdot P G_{t-j}+\sum_{j=0}^{c} \zeta_{j} \cdot P S_{t-j}+\sum_{j=0}^{d} \delta_{j} \cdot S_{t-j}+\sum_{j=0}^{e} \eta_{j} \cdot D_{t-j}+\theta_{1} \cdot \text { summer }+ \\
& \theta_{2} \cdot \text { winter }+\theta_{3} \cdot \text { spring }+v_{t}
\end{aligned}
$$

Where $t=(1, \ldots, T)$ is the number of time periods, $q_{t}(T \times 1)$ is a vector of the dependent variable, $P G_{t} P S_{t}, S_{t}, D_{t}(T \times 1)$ are the explanatory variables, $\alpha_{0}$ is the intercept, coefficients $\beta_{j}, \zeta_{j}, \delta_{j}$ and $\eta_{j}$ are scalars, and $v_{t}(T 1)$ is the vector of disturbances. The choice of $T$ will be based on the impact of lagged values of the dependent and independent variables on the current natural gas supply. All the variables in the model are in natural logarithms following a double-log specification.

The ARDL approach to cointegration consists of two stages based on the error correction specification of the ARDL. In the first stage a Wald test is conducted for the lagged level variables in the right-hand side of the corresponding unrestricted error correction model(ECM). Error correction models have the advantage to deliver short and long-run estimates of coefficients and are isomorphic with respect to autoregressive distributed lag models (ARDL) ${ }^{3}$. Equation 3 shows the corresponding unrestricted ECM for Equation 2.

$$
\begin{aligned}
& \Delta q_{t}=\alpha_{0}+\alpha_{1}^{*} q_{t-1}+\beta_{1}^{*} P G_{t-1}+\zeta_{1}^{*} P S_{t-1}+\delta_{1}^{*} S_{t-1}+\eta_{1}^{*} D_{t-1}+\beta_{0}^{*} \Delta P G_{t}+\zeta_{0}^{*} \Delta P S_{t}+\sum_{j=1}^{a-1} \tau_{j} \Delta q_{t-j}+ \\
& \sum_{j=1}^{b-1} \pi_{j} \Delta P G_{t-j}+\sum_{j=1}^{c-1} \phi_{j} \Delta P S_{t-j}+\sum_{j=1}^{d-1} \delta_{j} \Delta S_{t-j}+\sum_{j=1}^{e-1} \eta_{j} \Delta D_{t-j}+\theta_{0} \text { summer }+\theta_{1} \text { winter }+\theta_{2} \text { spring }+v_{t}
\end{aligned}
$$

Where the cointegration relation is defined as:

$$
\alpha_{1}^{*} q_{t-1}+\beta_{1}^{*} P G_{t-1}+\zeta_{1}^{*} P S_{t-1}+\delta_{1}^{*} S_{t-1}+\eta_{1}^{*} D_{t-1}=0
$$

The Wald's test null hypothesis is that there is no cointegration and tests that the coefficients on the lagged regressors (in levels) in the error correction form of the underlying ARDL model are jointly zero. This hypothesis is tested against the alternative hypothesis of cointegration.

\footnotetext{
${ }^{3}$ See Annex for conversion between ARDL and the unrestricted ECM
} 


$$
\begin{aligned}
& H_{0}: \hat{\alpha}_{1}^{*}=\hat{\beta}_{1}^{*}=\hat{\zeta}_{1}^{*}=\hat{\delta}_{1}^{*}=\hat{\eta}_{1}^{*}=0 \\
& H_{1}: \hat{\alpha}_{1}^{*} \neq \hat{\beta}_{1}^{*} \neq \hat{\zeta}_{1}^{*} \neq \hat{\delta}_{1}^{*} \neq \hat{\eta}_{1}^{*} \neq 0
\end{aligned}
$$

If $H_{0}$ is rejected at conventional levels of significance, we proceed to estimate the long and shortterm parameters by a two stage least square $(2 S L S)$. The critical values for the F-statistics are provided by Pesaran et al. (2001), where two sets of asymptotic critical values are presented. This provides a band covering all classification possibilities of the independent variables (purely $I(0)$, purely $I(1)$ or mutually cointegrated).

The instrumental variable approach to estimate supply and demand elasticities is used in order to solve the simultaneity problem that arises in supply and demand equations (Wright, 1928). The main idea is to use variables that explain one equation (i.e. demand) and shift it, to explain the other equation (i.e. supply). In this particular case, and since natural gas serves different purposes, we create an instrumental variable covering different end-uses.

Therefore our instrumental variable consists of real income (addressing the household and the energy generation sector) ${ }^{4}$ and of the industrial production index (addressing the industrial sector). For our instrumental variables we have conducted overidentification test, endogeneity tests and a test of jointly significance of the instruments, implying that the instruments applied are valid. The choice of lags used in the model is determined using the Schwarz's Bayesian information criterion (SBIC) for lag selection (Pesaran and Shin, 1995). For the purpose of our analysis we are mainly interested in the estimated coefficients $\beta_{0}$ and $\zeta_{0}$ in equation 2 . The estimated coefficient $\beta_{0}$ can be directly interpreted as the short-run own price elasticity of supply whereas long-run elasticities can be derived by the long-run equation. Parameter $\zeta_{0}$ delivers the cross price elasticity between crude oil and natural gas. For the long-run parameter we use the cointegration relation derived from estimating equation 4.

$$
\begin{aligned}
q^{*}= & \alpha_{0}+\sum_{j=1}^{a} \alpha_{j} q^{*}+\sum_{j=1}^{b} \beta_{j} P G^{*}+\sum_{j=1}^{c} \zeta_{j} P S^{*}+\sum_{j=1}^{d} \delta_{j} S^{*}+\sum_{j=1}^{e} \eta_{j} D^{*}+\theta_{0} \cdot \text { summer }+\theta_{1} \cdot \text { winter }+ \\
& \theta_{2} \cdot \text { spring }+v_{t}
\end{aligned}
$$

In order to obtain the long-run multiplication effect (LRM) of $P G_{t}$ with respect to $q_{t}$ it is only necessary to rearrange equation 6 .

$$
\begin{aligned}
q^{*}= & \frac{\hat{\alpha_{0}}}{1-\sum_{j=1}^{a} \hat{\alpha_{j}}}+\frac{\sum_{j=0}^{b} \hat{\beta_{j}}}{1-\sum_{j=1}^{a} \hat{\alpha_{j}}} \cdot P G^{*}+\frac{\sum_{j=0}^{c} \hat{\zeta_{j}}}{1-\sum_{j=1}^{a} \hat{\alpha_{j}}} \cdot P S^{*}+\frac{\sum_{j=0}^{d} \hat{\delta}_{j}}{1-\sum_{j=1}^{a} \hat{\alpha_{j}}} \cdot S^{*}+\frac{\sum_{j=0}^{e} \hat{\eta}_{j}}{1-\sum_{j=1}^{a} \hat{\alpha_{j}}} \cdot D^{*}+ \\
& \frac{\hat{\theta_{0}}}{1-\sum_{j=1}^{a} \hat{\alpha}_{j}} \cdot \text { winter }^{*}+\frac{\hat{\theta_{1}}}{1-\sum_{j=1}^{a} \hat{\alpha}_{j}} \cdot \text { summer }^{*}+\frac{\hat{\theta_{2}}}{1-\sum_{j=1}^{a} \hat{\alpha}_{j}} \cdot \text { spring }^{*}
\end{aligned}
$$

So that the long-run elasticity of supply is:

$$
L R M_{A R D L}=\frac{\sum_{j=0}^{b} \hat{\beta}_{j}}{1-\sum_{j=1}^{a} \hat{\alpha}_{j}}
$$

\footnotetext{
${ }^{4}$ The use of heating degree days was also considered but proved to have less power in explaining the variation of natural gas prices.
} 
Table 2: Despcriptive statistics

\begin{tabular}{llllllll}
\hline Variable & Description & Obs & Mean & Std. Dev. & Min & Max & Unit of measurement \\
\hline$q$ & Natural gas supply & 303 & 47251 & 4293 & 37699 & 61363 & million cubic meters \\
$\log q$ & Marketed production & 303 & 10.8 & 0.1 & 10.54 & 11.02 & \\
\hline$P G$ & Natural gas & 303 & 2.3 & 0.9 & 0.77 & 5.18 & US Dollars per MBTU \\
$\log P G$ & wellhead price & 303 & 0.8 & 0.4 & -0.27 & 1.64 & \\
\hline$P S$ & Crude oil price (WTI) & 303 & 71.3 & 77.0 & 11.29 & 361.82 & US Dollars per barrel \\
$\log P S$ & & 303 & 3.8 & 1.0 & 2.42 & 5.89 & \\
\hline$S$ & Storage working gas & 303 & 185761 & 20536 & 142773 & 234878 & million cubic meters \\
$\log S$ & (reserves underground) & 303 & 12.1 & 0.1 & 11.87 & 12.37 & \\
\hline$D$ & US natural gas rotary & 303 & 720 & 362 & 250 & 1585 & number of rigs \\
$\log D$ & rigs in operation & 303 & 6.5 & 0.5 & 5.52 & 7.37 & in operation \\
\hline winter & binary variable & 303 & 0.25 & 0.4 & 0 & 1 & $1-0$ \\
summer & binary variable & 303 & 0.25 & 0.4 & 0 & 1 & $1-0$ \\
spring & binary variable & 303 & 0.25 & 0.4 & 0 & 1 & $1-0$ \\
\hline ipi & monthly industrial & 303 & 81 & 14 & 56 & 101 & Index \\
$\log$ ipi & production & 4.4 & 0.2 & 4.02 & 4.61 & & \\
\hline inc & real monthly & 303 & 8582 & 1837 & 5578 & 11479 & Billions of chained \\
$\log$ inc & income & 303 & 9.0 & 0.2 & 8.63 & 9.35 & 2009 US Dollars \\
\hline
\end{tabular}

${ }^{1}$ Marketed production is used as a proxi for natural gas production

And can also be derived from equation 3 as:

$$
L R M_{E C M}=\frac{\hat{\beta}_{1}^{*}}{\hat{\alpha}_{1}^{*}}
$$

Due to the isomorphic nature of the ARDL and unrestricted ECM, the results will be identical. The long-run multiplier effect can be interpreted as the total effect $P G$ has on $q$, distributed over future time periods. Since we are dealing with elasticities of supply, we would expect in the short-run, coefficients $\beta_{0}$ and $\zeta_{0}$ to be very small and near to zero, since to react to price changes producers will need more than a month. In the long-run we expect natural gas elasticities of supply to be positive as opposite to $\zeta_{0}$. Since crude oil and natural gas compete with each other in the extraction phase, we would expect to see that if prices for crude oil increase supply of natural gas would decrease. For the own price elasticity of supply a positive result would imply that the higher the price increases, producers would try to sell more units and as a logical consequence increase their production. This corresponds to the theory of supply and demand.

\section{DATA}

The data utilized for the estimation of the natural gas supply response to price in the United States is public available data obtained from the US Energy Information Administration (EIA), the US National Climatic Data Center (NCDC) and the Federal Reserve Economic Database (FRED) on a monthly basis from August 1987 to October 2012 providing 303 observations.

Aggregated supply $(q)$ was approximated by using US production as proxy. The explanatory variables are: the natural gas wellhead prices $(P G)$ as the supplier's price; crude oil price $(P S)$ based on the Western Texas Intermediate emphasizing the substitute energy source from the supplier's side; working gas in storage $(S)$; drilling activity $(D)$ measured by the amount of 
natural gas rigs in operation and seasonal dummy variables (winter, summer and spring). For the second step in our strategy we identified US real monthly income (inc) and the US monthly production index (ipi) as reasonable instruments for real natural gas prices. Logarithms of all variables were used and energy prices were deflated using the consumer price index for energy products (U.S. Department of Labor). Table 2 summarizes all variables with their main descriptive statistics.

One of the requirements of this approach is the exception of variables that are integrated of order 2 or higher. Three different unit root tests -the Augmented Dickey Fuller ADF, the Dickey Fuller General Least Square DFGLS and the Phillips-Perron PP tests- are performed to test for unit roots. The use of different unit root test should increment the power of the results. Table 3 presents the results and shows clearly that non of the variables are integrated of order two $I(2)$. Still the tests show some inconsistencies: (1) the $A D F$ as well as the DFGLS test both show that all variables are non-stationary in levels and therefore $I(1)$. On the contrary, the $P P$ test shows that the log of production $\log (q)$ and the $\log$ of storage $\log (S)$ are both stationary in levels. The unit roots test do not provide a clear answer on the integration order of the variables at their levels. (2) but two out of three of the test conclude that all of the variables are stationary on their first differences. Hence we can proceed to implement the ARDL Bound cointegration approach, which can be implemented irrespective of whether the variables are $I(0), I(1)$ or a mix of them.

Table 3: Unit Root Tests

\begin{tabular}{|c|c|c|c|c|c|c|c|c|c|c|c|}
\hline \multirow[b]{2}{*}{ Variable } & \multirow[b]{2}{*}{ Trend } & \multicolumn{5}{|c|}{ Level } & \multicolumn{5}{|c|}{ First Differences } \\
\hline & & $\mathrm{ADF}$ & & DFGLS $^{1,2}$ & & PP & ADF & & DFGLS $^{1,2}$ & & PP \\
\hline \multirow[t]{2}{*}{$\log q$} & No & 0.592 & (7) & 2.621 & (12) & $-4.629^{* * *}$ & $-10.786^{* * *}$ & (6) & -0.120 & (15) & $-41.739^{* * *}$ \\
\hline & Yes & -0.959 & (7) & -0.968 & (12) & $-9.177^{* * *}$ & $-10.903^{* * *}$ & (6) & -1.906 & (15) & $-41.70^{* * *}$ \\
\hline $\log P G$ & No & -2.190 & (2) & -1.377 & (11) & -2.221 & $-11.670^{* * *}$ & (2) & $-3.444^{* * *}$ & (10) & $-14.820^{* * *}$ \\
\hline \multirow[t]{2}{*}{$\log P S$} & No & -0.278 & (1) & 0.790 & (13) & -0.670 & $-8.873^{* * *}$ & (2) & $-3.090^{* * *}$ & (13) & $-11.477^{* * * x}$ \\
\hline & Yes & -2.246 & (1) & -1.428 & (13) & -2.772 & $-8.874^{* * *}$ & (2) & $-5.146^{* * *}$ & (12) & $-11.467^{* * *}$ \\
\hline \multirow[t]{2}{*}{$\log S$} & No & -1.720 & (7) & -1.731 & (15) & $-6.160 * * *$ & $-20.331^{* * *}$ & (7) & -0.758 & (14) & $-6.954^{* * *}$ \\
\hline & Yes & -3.008 & (7) & -1.925 & (15) & $-6.498^{* * *}$ & $-20.364^{* * *}$ & (7) & -1.885 & (14) & $-6.951^{* * *}$ \\
\hline $\log D$ & No & -1.472 & (4) & -1.137 & (11) & -1.681 & $-8.897^{* * *}$ & (3) & $-2.394^{* * *}$ & (10) & $-8.747^{* * *}$ \\
\hline
\end{tabular}

Lags are given in parenthesis. Two asterisks indicate significance at 5\% level, and three asterisks, at the $1 \%$ level.

${ }^{1}$ uses ESR critical values

2 selected by (Ng and Perron, 1995)

\section{Results}

We first determine the lag structure of the ARDL by minimizing the Schwarz's Bayesian information criterion (SBIC) to then derive and estimate the unrestricted ECM by two stage least squares (2SLS). For lag structure we find an ARDL $(13,3,2,13,2)$

$$
\begin{aligned}
q_{t}= & \alpha_{0}+\sum_{j=1}^{13} \alpha_{j} \cdot q_{t-j}+\sum_{j=0}^{3} \beta_{j} \cdot P G_{t-j}+\sum_{j=0}^{2} \zeta_{j} \cdot P S_{t-j}+\sum_{j=0}^{13} \delta_{j} \cdot S_{t-j}+\sum_{j=0}^{2} \eta_{j} \cdot D_{t-j}+\theta_{1} \cdot \text { summer } \\
& +\theta_{2} \cdot \text { winter }+\theta_{3} \cdot \text { spring }+v_{t}
\end{aligned}
$$

The unrestricted ECM that will be estimated is defined as: 


$$
\begin{aligned}
& \Delta q_{t}=\alpha_{0}+\alpha_{1}^{*} q_{t-1}+\beta_{1}^{*} P G_{t-1}+\zeta_{1}^{*} P S_{t-1}+\delta_{1}^{*} S_{t-1}+\eta_{1}^{*} D_{t-1}+\beta_{0}^{*} \Delta P G_{t}+\zeta_{0}^{*} \Delta P S_{t}+\sum_{j=1}^{12} \rho_{j} \Delta q_{t-j}+ \\
& \sum_{j=1}^{2} \beta_{j} \Delta P G_{t-j}+\sum_{j=1}^{1} \phi_{j} \Delta P S_{t-j}+\sum_{j=1}^{12} \delta_{j} \Delta S_{t-j}+\sum_{j=1}^{1} \eta_{j} \Delta D_{t-j}+\theta_{0} \cdot \text { summer }+\theta_{1} \cdot \text { winter }+\theta_{2} \cdot \text { spring }+v_{t}
\end{aligned}
$$

The ARDL cointegration approach developed by (Pesaran and Shin, 1995) and (Pesaran et al., 2001) is based on an F-test of the first lags of the dependent and independent variables. Our results provide empirical support for the existence of a stable long-run relation among natural gas supply, natural gas prices, crude oil prices, storage and drilling activity $(q, P G, P S, S, D)$ when supply is modeled as the dependent variable (see Table 4). The computed F-statistic is above the range provided by the critical values. This result was expected and needed in order to estimate long-run elasticities of supply.

Table 4: F-test for cointegration

\begin{tabular}{ll}
\hline Computed F-statistic & 5.43 \\
P-value & $(0.0001)$ \\
Bound test critical values at 1\% & 3.41 (lower) \\
& 4.68 (upper) \\
\hline Bound test critical values extracted from Pesaran et al. (2001), & \\
p. 300 Table CI (iii) Case III: Unrestricted intercept and no trend &
\end{tabular}

Estimating the ARDL as specified in equation 8 as well as the unrestricted ECM in equation 11 provide two types of results (see appendix B). The estimated coefficients of the main variables of interest are marked in bold, and as shown in section 2, identical. In the very short-run, the elasticity of supply does not differ from zero, given its low statistical significance. This implies that no immediate adjustment is seen during the shock period, meaning that producers do no react to changes in price instantly. Our analysis implies that after a period of one month, the change in market supply can be explained ceteris paribus by a change in natural gas prices. The effect on the price of crude oil on supply is not immediate either. And no influence of crude price on supply can be observed at any further period. In the substitutes case The same result can be observed for the natural gas substitute (crude oil). Both these results agree with our expectations. Both models deliver short-run elasticities directly. In order to derive the long-run elasticities we calculate equation 8 using the estimated coefficients from the empirical analysis. The long-run equilibrium is the value to which the changes in supply would tend after shocks have altered the long-term relationship in the model. When the shocks are absorbed, the model will go back to its equilibrium.

Table 6 (in Annex B) summarizes the long-run elasticities and provides the corresponding standard error. Thus we can observe that the long-run price elasticity of supply is statistically significant at the $5 \%$ level, is positive as expected, and is about 0.76 . From this result we infer that the long run supply curve for natural gas is a rather inelastic one meaning that producers react slowly to changes in prices. The long-run cross price elasticity shows a negative sign following our expectations but is statistically insignificant. Thus implying it is not different from zero. The adjustment coefficient of the autoregressive distributed lag model is 0.0557 and determines that after a shock the model achieves equilibrium after almost 18 periods $(1 / 0.0557)$.

The production of natural gas is a rather complex process that requires not only high investments. 
Table 5: Results of diagnostic tests

\begin{tabular}{lrc}
\hline Test & Statistic & Prob. \\
\hline $\begin{array}{l}\text { Overidentification } \\
\text { Sargan } \mathrm{Chi}^{2}\end{array}$ & 0.20 & 0.89 \\
\hline $\begin{array}{l}\text { Strenght of Instrument } \\
\text { F-Statistic }\end{array}$ & 11.16 & 0.00 \\
\hline
\end{tabular}

It is a time demanding process that starts with exploration activities long before natural gas can be extracted from the well. The natural gas extracted at the well cannot be used in that form and therefore must be conditioned and transported before reaching the end-consumer. The high investments required in this particular industry and the long time needed to complete the value chain is what in our point of view makes producer react rather slowly towards prices. Therefore no reaction is observed in the very short-run (one month).

Post-estimation tests were conducted to test for the strength of the selected instruments and for misspecification. The use of more than one instrument leads us to test for overidentification. The results are gathered in Table 5 and show a joint significance different from zero. Instruments with an F-statistic larger than 10 are considered sufficiently strong for a $2 S L S$ estimation. The overidentification test, tests whether the instruments are uncorrelated with the error term and if the equation is misspecified. Here the test reassures our specification.

\section{Conclusion}

In this paper we have econometrically analyzed the reaction of natural gas producers to prices in a competitive natural gas market. Therefore we have estimated long and short-run own price elasticities of supply in the US natural gas sector using the ARDL approach to cointegration developed by Pesaran et al. (2001). Our analysis identified no responsiveness from producers towards prices in the very short run. This is consistent with the infrastructure costs that arise when the producer wants to increase its production. On the long-run we estimated the own price elasticity of supply at 0.76 . This result means that in this particular case (United States) we are dealing with an inelastic supply curve since a one-percent change in wellhead natural gas prices, would lead to a 0.76 percent change in supply. Our paper gives a hint on the relation between producers and market prices in a competitive market suggesting that producers do not react strongly to price changes.

\section{REFERENCES}

Barret, C. (1992). U.S Natural gas Market: A Desiquilibrium Approach. In Intrnational Association for Energy Economics 15th Intenrational Conference, Coping with the Energy future: Markets and Regulations, Maz 18-20,1992, Tours, France.

BP (2013). BP Statistical Review of World Energy.

Chermak, J. and R. Patrick (1995). A Well Based Cost Function and the Economies of Exhaustible Natural Resources: The Case of Natural Gas. Journal of Environmental Economics and Management 28, 174-189.

Cleveland, C. (2009). Concise Encyclopedia of the History of Energy. Academic Press. 
Dahl, C. (1992). Regional Cost of Natural Gas. Technical report, American Gas Association.

Dahl, C. (2007). Energy Demand Elasticity Survey: A Primer and Progress Report. draft manuscript.

Dahl, C. and T. Duggan (1996). US energy product supply elasticities: A survey and application to the US oil market. Resource and Energy Economic 18, 243-263.

EIA (2013). Annual Energy Outlook 2013 with Projections to 2040. U.S. Energy Information Administration.

Erickson, E. and R. Spann (1971). Supply Response in a Regulated Industry; The Case of Natural Gas. The Bell Journal of Economics and Management Science 2, 94-121.

Granger, C. W. J. and P. Newbold (1974). Spurious regressions in econometrics. Journal of Econometrics 2, 111-120.

Inder, B. (1993). Estimating Long-Run Relationships in Economics: A Comparison of Different Approaches. Journal of Econometrics 57, 53 Ü68.

Krichene, N. (2002). World Crude Oil and Natural Gas: A Demand and Supply. Energy Economics 24, 557-576.

Mc Avoy, P. W. (2000). The Natural Gas Market. Sixty Years of Regulation and Deregulation. Yale University Press.

Medlock III, K. (2012). US LNG Exports: Truth and Consequence. Technical report, James A. Baker III Institute for Public Policy, Rice University.

Ng, S. and P. Perron (1995). Unit Root Tests in ARMA Models with Data-Dependent Methods for the Selection of the Truncation Lag. Journal of the American Statistical Association 90, 268 Ü281.

Pesaran, M. and Y. Shin (1995). Long-Run Structural Modeling. Technical report, Cambridge Working Papers in Economics, Faculty of Economics, University of Cambridge.

Pesaran, M., Y. Shin, and R. Smith (2001). Bounds Testing Approaches to the Analysis of Level Relationship. Journal of Applied Econometrics 16, 289-326.

Raymond, M. and W. Leffler (2006). Oil and Gas Production in Nontechnical Language. Penn Well Corporation.

Wright, P. G. (1928). The Tariff on Animal and Vegetable Oils,, Chapter Appendix B, pp. 286-304. MacMillan.

Yule, U. (1926). Why do we Sometimes get Nonsense-Correlations between Time-Series? A Study in Sampling and the Nature of Time-Series. Journal of the Royal Statistical Society 89(1), 1-63. 


\section{A. AnNex 1: ARDL MOdel to UnRestricted ECM}

Since autoregressive distributed lag models and error correction models are isomorphic, taking $q_{t-1}$ on both sides in equation 2 yields, the following ECM. For explanation purposes the transformation will be conducted on an ARL $(a, b, c)$ :

$$
\begin{gathered}
q_{t}=\alpha_{0}+\sum_{j=1}^{a} \alpha_{j} \cdot q_{t-j}+\sum_{j=0}^{b} \beta_{j} \cdot P G_{t-j}+\sum_{j=0}^{c} \zeta_{j} \cdot P S_{t-j}+v_{t} \\
\Delta q_{t}=\alpha_{0}+\left(\alpha_{1} \cdot q_{t-1}-q_{t-1}+\alpha_{2} \cdot q_{t-2}+\ldots+\alpha_{j} \cdot q_{t-j}\right)+\left(\beta_{0} \cdot P G_{t}+\beta_{1} \cdot P G_{t-1}+\beta_{2} \cdot P G_{t-2}+\ldots\right. \\
\left.+\beta_{j} \cdot P G_{t-j}\right)+\left(\zeta_{0} \cdot P S_{t}+\zeta_{1} \cdot P S_{t-1}+\zeta_{2} \cdot P S_{t-2}+\ldots+\zeta_{j} \cdot P S_{t-j}\right)+v_{t}
\end{gathered}
$$

Equation 13 can be simplified as:

$$
\Delta q_{t}=\alpha_{0}+\sum_{j=1}^{a} \alpha_{j} \cdot q_{t-j}-q_{t-1}+\sum_{j=1}^{b} \beta_{j} \cdot P G_{t-j}+\sum_{j=1}^{c} \zeta_{j} \cdot P S_{t-j}+v_{t}
$$

And arranged as:

$$
\begin{aligned}
\Delta q_{t}= & \alpha_{0}+\left[\left(\alpha_{1}+\alpha_{2}+\ldots+\alpha_{j-1}\right) q_{t-1}+\left(\tau_{1} \Delta q_{t-1}-\ldots-\tau_{a-1} \Delta q_{t-(a-1)}\right]+\right. \\
& {\left[\left(\beta_{0}+\beta_{1}+\beta_{2}+\ldots+\beta_{j-1}\right) P G_{t-1}+\left(\pi_{0} \Delta P G_{t}-\pi_{1} \Delta P G_{t-1}-\ldots-\pi_{a-1} \Delta P G_{t-(b-1)}\right]+\right.} \\
& {\left[\left(\zeta_{0} \zeta_{1}+\zeta_{2}+\ldots+\zeta_{j-1}\right) P S_{t-1}+\left(\phi_{0} \Delta P S_{t}-\phi_{1} \Delta P S_{t-1}-\ldots-\phi_{a-1} \Delta P S_{t-(c-1)}\right]+v_{t}\right.}
\end{aligned}
$$

The parameters can then be simplified in order to allow an easier interpretation, so that:

$$
\begin{gathered}
\left(\alpha_{1}+\alpha_{2}+\ldots+\alpha_{j}-1\right)=\alpha^{*} \\
\left(\beta_{0}+\beta_{1}+\beta_{2}+\ldots+\beta_{j}\right)=\beta^{*} \\
\left(\zeta_{0}+\zeta_{1}+\zeta_{2}+\ldots+\zeta_{j}\right)=\zeta^{*} \\
\Delta q_{t}=\alpha_{0}+\left[\alpha^{*} q_{t-1}+\left(\tau_{1} \Delta q_{t-1}+\ldots+\tau_{a-1} \Delta q_{t-(a-1)}\right)\right]+ \\
{\left[\left(\beta^{*} P G_{t-1}+\left(\pi_{0} \Delta P G_{t}-\pi_{1} \Delta P G_{t-1}-\ldots-\pi_{b-1} \Delta P G_{t-(b-1)}\right]+\right.\right.} \\
{\left[\left(\zeta^{*} P S_{t-1}+\left(\phi_{0} \Delta P S_{t}-\phi_{1} \Delta P S_{t-1}-\ldots-\phi_{c-1} \Delta P S_{t-(c-1)}\right]+v_{t}\right.\right.}
\end{gathered}
$$

Which can be simplified to an unrestricted ECM:

$$
\begin{aligned}
\Delta q_{t}= & \alpha_{0}+\alpha_{1}^{*} q_{t-1}+\beta_{1}^{*} P G_{t-1}+\zeta_{1}^{*} P S_{t-1}+\beta_{0}^{*} \Delta P G_{t}+\zeta_{0}^{*} \Delta P S_{t}+\sum_{j=1}^{a-1} \tau_{j} \Delta q_{t-j}+ \\
& \sum_{j=1}^{b-1} \pi_{j} \Delta P G_{t-j}+\sum_{j=1}^{c-1} \phi_{j} \Delta P S_{t-j}+\sum_{j=1}^{d-1}
\end{aligned}
$$

\section{B. AnNex 2: Results}


Table 6: Estimation results : ARDL and ECM (IV Regression)

\begin{tabular}{|c|c|c|c|c|c|}
\hline \multicolumn{3}{|c|}{ ARDL } & \multicolumn{3}{|c|}{ ECM } \\
\hline Variable & Coefficient & (Std. Err.) & Variable & Coefficient & (Std. Err.) \\
\hline Supplyt-1 & $0.499^{* * *}$ & $(0.056)$ & $\Delta S u p p l y_{t-1}$ & $-0.446^{* * *}$ & $(0.058)$ \\
\hline Supplyt-2 & $0.202^{* * *}$ & $(0.047)$ & $\Delta$ Supply $_{t-2}$ & $-0.243^{* * *}$ & $(0.069)$ \\
\hline Supplyt-3 & -0.019 & $(0.064)$ & $\Delta S u p p l y_{t-3}$ & $-0.262^{* * *}$ & $(0.087)$ \\
\hline Supplyt-4 & -0.091 & $(0.059)$ & $\Delta S$ Suply ${ }_{t-4}$ & $-0.353^{* * *}$ & $(0.072)$ \\
\hline Supplyt-5 & -0.006 & $(0.052)$ & $\Delta$ Supply ${ }_{t-5}$ & $-0.359^{* * *}$ & $(0.066)$ \\
\hline Supply $_{t-6}$ & 0.031 & $(0.052)$ & $\Delta$ Supply $y_{t-6}$ & $-0.328^{* * *}$ & $(0.066)$ \\
\hline Supplyt-7 & -0.003 & $(0.055)$ & $\Delta$ Supplyt-7 & $-0.331^{* * *}$ & $(0.069)$ \\
\hline Supplyt-8 & -0.023 & $(0.042)$ & $\Delta$ Supply ${ }_{t-8}$ & $-0.354^{* * *}$ & $(0.073)$ \\
\hline Supplyt-9 & $0.142^{* * *}$ & $(0.053)$ & $\Delta$ Supply $y_{t-9}$ & $-0.212^{* * *}$ & $(0.061)$ \\
\hline Supplyt-10 & 0.015 & $(0.052)$ & $\Delta$ Supplyt-10 & $-0.197^{* * *}$ & $(0.063)$ \\
\hline Supplyt-11 & $-0.072^{*}$ & $(0.041)$ & $\Delta$ Supplyt-11 & $-0.269^{* * *}$ & $(0.063)$ \\
\hline Supply $_{t-12}$ & $0.593^{* * *}$ & $(0.060)$ & $\Delta$ Supplyt-12 & $0.324^{* * *}$ & (0.053) \\
\hline Supplyt-13 & $-0.324^{* * *}$ & $(0.053)$ & & & \\
\hline Naturalgas $t$ & -0.048 & $(0.048)$ & $\Delta$ Naturalgas $t$ & -0.048 & $(0.048)$ \\
\hline Naturalgas $t_{-1}$ & 0.063 & $(0.048)$ & $\Delta$ Naturalgas $t-1$ & $0.056^{* * *}$ & $(0.015)$ \\
\hline Naturalgas $_{t-2}$ & $-0.050^{* * *}$ & $(0.022)$ & $\Delta$ Naturalgas $s_{t-2}$ & 0.006 & $(0.016)$ \\
\hline Naturalgas $_{t-3}$ & -0.006 & $(0.016)$ & & & \\
\hline CrudeOil & 0.001 & $(0.013)$ & $\Delta$ CrudeOil & 0.001 & $(0.013)$ \\
\hline CrudeOil $_{t-1}$ & -0.002 & $(0.022)$ & $\Delta$ CrudeOil $_{t-1}$ & -0.002 & $(0.014)$ \\
\hline CrudeOil $_{t-2}$ & 0.002 & $(0.014)$ & & & \\
\hline Storage $_{t-1}$ & $-0.269 * *$ & $(0.132)$ & $\Delta$ Storage $_{t-1}$ & $-0.294^{* *}$ & $(0.136)$ \\
\hline Storage $_{t-2}$ & $0.296^{*}$ & $(0.180)$ & $\Delta$ Storage $_{t-2}$ & 0.001 & $(0.096)$ \\
\hline Storage $_{t-3}$ & -0.037 & $(0.139)$ & $\Delta$ Storage $_{t-3}$ & -0.036 & $(0.098)$ \\
\hline Storage $_{t-4}$ & -0.123 & $(0.151)$ & $\Delta$ Storage $_{t-4}$ & -0.158 & $(0.120)$ \\
\hline Storage $_{t-5}$ & 0.076 & $(0.148)$ & $\Delta$ Storage $_{t-5}$ & -0.082 & $(0.090)$ \\
\hline Storage $_{t-6}$ & -0.039 & $(0.132)$ & $\Delta$ Storage $_{t-6}$ & -0.121 & (0.092) \\
\hline Storage $_{t-7}$ & 0.063 & $(0.136)$ & $\Delta$ Storage $_{t-7}$ & -0.058 & $(0.088)$ \\
\hline Storage $_{t-8}$ & 0.024 & $(0.138)$ & $\Delta$ Storage $_{t-8}$ & -0.034 & $(0.087)$ \\
\hline Storage $_{t-9}$ & $-0.226^{*}$ & $(0.132)$ & $\Delta$ Storage $_{t-9}$ & $-0.260^{* * *}$ & $(0.090)$ \\
\hline Storage $_{t-10}$ & -0.044 & $(0.135)$ & $\Delta$ Storage $_{t-10}$ & $-0.304^{* * *}$ & $(0.085)$ \\
\hline Storage $_{t-11}$ & 0.156 & $(0.139)$ & $\Delta$ Storage $_{t-11}$ & -0.148 & $(0.091)$ \\
\hline Storage $_{t-12}$ & -0.064 & $(0.135)$ & $\Delta$ Storage $_{t-12}$ & $-0.212^{* *}$ & $(0.088)$ \\
\hline Storage $_{t-13}$ & $0.212^{* * *}$ & $(0.088)$ & & & \\
\hline DrillingAct.t-1 & $0.051^{*}$ & $(0.026)$ & $\Delta$ Drilling Act.t-1 & 0.025 & $(0.024)$ \\
\hline \multirow[t]{6}{*}{ Drilling Act.t-2 } & -0.025 & $(0.024)$ & & & \\
\hline & & & Supply $y_{t-1}$ & $-0.056^{* *}$ & $(0.028)$ \\
\hline & & & Naturalgas $s_{t-1}$ & $-0.042^{* * *}$ & $(0.012)$ \\
\hline & & & CrudeOil $_{t-1}$ & 0.002 & $(0.004)$ \\
\hline & & & Storage $_{t-1}$ & 0.025 & $(0.055)$ \\
\hline & & & Drilling Act. $t-1$ & $0.026^{* * *}$ & $(0.009)$ \\
\hline summer & $0.045^{* * *}$ & $(0.015)$ & summer & $0.045^{* * *}$ & $(0.015)$ \\
\hline winter & -0.018 & $(0.018)$ & winter & -0.018 & $(0.018)$ \\
\hline spring & $0.060^{* * *}$ & $(0.021)$ & spring & $0.060^{* * *}$ & $(0.021)$ \\
\hline Intercept & 0.135 & $(0.721)$ & Intercept & 0.135 & $(0.721)$ \\
\hline \multicolumn{6}{|c|}{ LONG RUN MULTIPLIERS } \\
\hline NaturalGas & $0.758^{* *}$ & $(0.332)$ & & & \\
\hline CrudeOil & -0.0290 & $(0.0629)$ & & & \\
\hline Storage & -0.4551 & $(1.0172)$ & & & \\
\hline DrillingAct. & $-0.4646^{* *}$ & $(0.2268)$ & & & \\
\hline
\end{tabular}

$*, * * * * *$ indicate significance at the $10 \%$ level, $5 \%$ level and $1 \%$ level. 